\title{
Evidence of SARS-CoV-2 infection in gallbladder and aggravating cholecystitis to septic shock: a case report
}

\author{
Xiaopeng Hong ${ }^{1 \#}$, Jianzhong $\mathrm{He}^{2 \#}$, Peiping $\mathrm{Li}^{1 *}$, Jiafan Chen ${ }^{1}$, Baojia Zou ${ }^{1}$, Zhanyu Li ${ }^{2}$, Yingbin Jia ${ }^{1}$, \\ Ye Liu ${ }^{2}$, Lukun Yang ${ }^{3}$, Jian $\mathrm{Li}^{1}$ \\ ${ }^{1}$ Department of Hepatobiliary Surgery, the Fifth Affiliated Hospital, Sun Yat-sen University, Zhuhai, China; ${ }^{2}$ Department of Pathology, the Fifth \\ Affiliated Hospital, Sun Yat-sen University, Zhuhai, China; ${ }^{3}$ Department of Anesthesiology, the Fifth Affiliated Hospital, Sun Yat-sen University, \\ Zhuhai, China \\ "These authors contributed equally to this work. \\ Correspondence to: Jian Li. Department of Hepatobiliary Surgery, the Fifth Affiliated Hospital, Sun Yat-sen University, 52 East Meihua Road, Zhuhai \\ 519000, China. Email: lijian5@mail.sysu.edu.cn; Lukun Yang. Department of Anesthesiology, the Fifth Affiliated Hospital, Sun Yat-sen University, \\ 52 East Meihua Road, Zhuhai 519000, China. Email: yanglk@mail.sysu.edu.cn; Ye Liu. Department of Pathology, the Fifth Affiliated Hospital, Sun \\ Yat-sen University, 52 East Meihua Road, Zhuhai 519000, China. Email: 1y77219@163.com.
}

\begin{abstract}
Coronavirus disease 2019 (COVID-19) has threatened human health worldwide and could lead to multiple organs injury. However, the impact on the virus infecting the biliary system, especially the gallbladder, has remained unclear and no pathological evidence has been reported yet. A case of SARSCoV-2 infection in a gallbladder with cholecystitis, which progressed rapidly to sepsis and required an emergency operation was investigated and reported. Clinical specimens of the COVID-19 patient including serum, oropharyngeal swabs, sputum, bile, abdominal drainage fluid, urine, stool, and gallbladder tissue were collected and tested for SARS-CoV-2 RNA using a quantitative polymerase chain reaction (qPCR) assay. Fresh normal gallbladder tissue and gangrenous gallbladder tissue were also collected for further research including hematoxylin and eosin (HE), immunohistochemistry (IHC), and immunofluorescent (IF) staining, and compared with the gallbladder from the COVID-19 patient. The bile, as well as the serum, oropharyngeal swabs, sputum, abdominal drainage fluid, urine, and rectal swabs were consecutively negative for SARS-CoV-2 RNA. The viral host receptor angiotensin-converting enzyme 2 (ACE2) was highly expressed in gallbladder epithelial cells, and viral nucleocapsid protein (NP) was visualized in the cytoplasm of gallbladder epithelial cells. Immune cells including CD2, CD3, CD4, CD8, CD20, CD38, CD68, and MPO were positive in gangrenous gallbladder tissues without SARS-CoV-2 infection, and were relatively downregulated in SARS-CoV-2 infective gallbladder tissue. This study provided evidence of SARS-CoV-2 infection in the gallbladder and verified that the gallbladder was one of the target organs that SARS-CoV-2 could attack and damage using ACE2 as a cell receptor. Due to the immune dysregulation involved, more vigilant management and early assessment is needed for COVID-19 patients with the comorbidity of cholecystitis.
\end{abstract}

Keywords: SARS-CoV-2; cholecystitis; angiotensin-converting enzyme 2; septic shock; case report

Submitted Aug 26, 2021. Accepted for publication Oct 20, 2021.

doi: $10.21037 / \mathrm{atm}-21-4778$

View this article at: https://dx.doi.org/10.21037/atm-21-4778

\section{Introduction}

Coronavirus disease 2019 (COVID-19), caused by the novel virus of severe acute respiratory syndrome coronavirus 2 (SARS-CoV-2), has spread quickly, posing a serious threat to human health worldwide (1-3). It has been clearly verified that the virus of SARS-CoV-2 can transmit through droplets and person to person contact $(4,5)$. It also has been shown that live SARS-CoV-2 can be found in the stool 


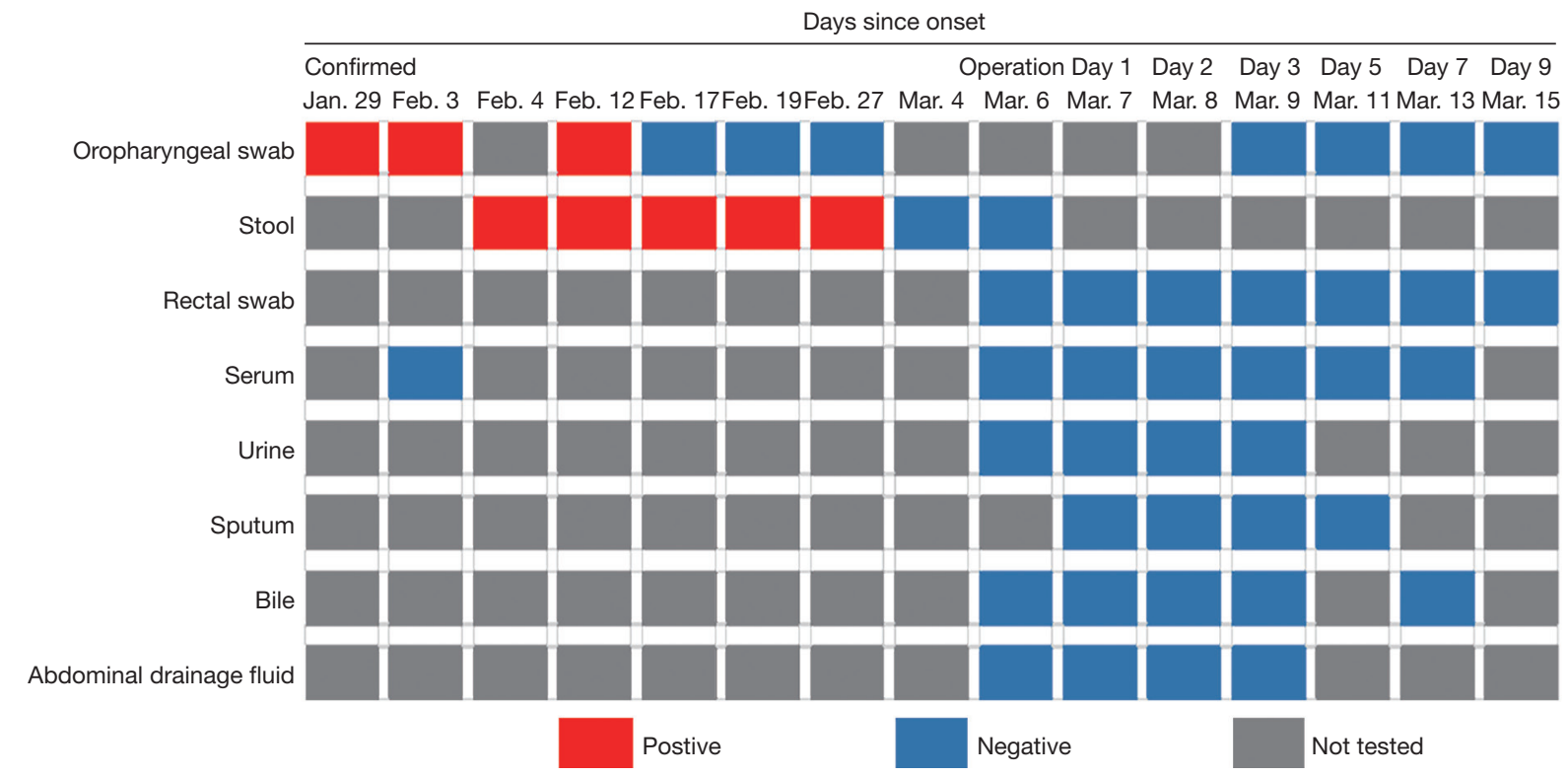

Figure 1 Results of quantitative polymerase chain reaction testing for COVID-19, 29 January to 15 March 2020. Red square means positive, blue square means negative, and grey square means not tested.

specimens in COVID-19 patients, indicating the potential fecal-oral transmission (6). However, the other avenues of transmission from other fluids such as bile or digestive juice have remained unknown.

It has been demonstrated that SARS-CoV-2 shares the same host cell receptor of ACE2 with SARS for entry process and could attack multiple organs including the lungs, liver, kidneys, and lower gastrointestinal tract (7-11). Xiao et al. had observed the intracellular staining of viral nucleocapsid protein in gastric, duodenal, and rectal epithelia demonstrating SARS-CoV-2 could infect gastrointestinal glandular epithelial cells (11). However, the impact of the virus infecting the biliary system, especially the gallbladder, has remained unclear and no pathological evidence has been reported yet. Immune dysregulation, such as inflammatory cytokine storm and lymphopenia, has been reported and understood to play an important role in processes of different pathological damages in COVID-19 patients (12-14). This case described a COVID-19 patient who had the comorbidity of acute calculous cholecystitis, and underwent an emergency operation due to biliary infection rapidly progressing to sepsis. Although we found the negative testing for SARS-CoV-2 in the bile, we verified that the gallbladder was one of the target organs that SARS-CoV-2 could attack and damage using ACE2 as a cell receptor. We first demonstrated the evidence of SARS-
$\mathrm{CoV}-2$ infection in the gallbladder and further investigated whether the dual strike of viral and bacterial infection precipitating immune dysregulation might aggravate the biliary infection towards sepsis. In addition, we confirmed that there was no contiguity of bile after double negative tests of oropharyngeal swab and stool for SARS-CoV-2 RNA. We present the following article in accordance with the CARE reporting checklist (available at https://dx.doi. org/10.21037/atm-21-4778).

\section{Case presentation}

The patient (male, 69 years old) was diagnosed with COVID-19 after 2 consecutively positive SARS-CoV-2 RNA oropharyngeal swab test results on 29 January 2020 and 3 February 2020. After appropriate treatments, the SARS-CoV-2 RNA in oropharyngeal swabs tested negative on 17 February 2020 and 19 February 2020, respectively. His stool first tested positive on 4 February 2020 and did not turn negative until 4 March 2020 (Figure 1).

Apart from a history of hypertension, the patient had asymptomatic gallstones in the gallbladder and common bile duct. During his hospital stay for COVID-19 treatment, a normal gallbladder without edema and exudation was shown on the routine abdominal computed tomography (CT) scan on 17 February 2020 (Figure S1). On the night 
Table 1 Laboratory data and clinical information

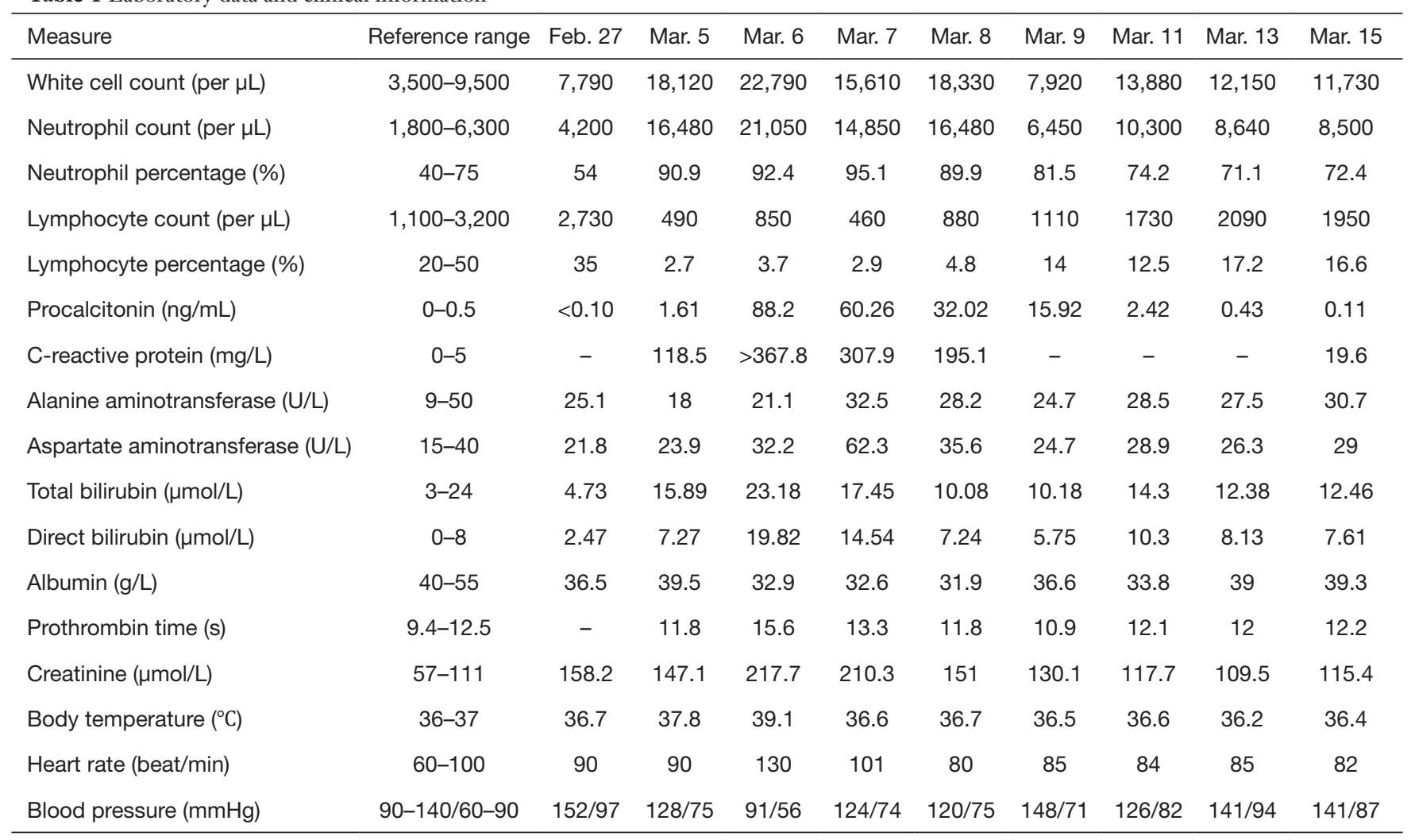

of 4 March 2020, the patient experienced the first episode of slight abdominal pain in the right upper abdominal quadrant. The pain reduced and then increased on 5 March 2020. Meanwhile, the physical examination revealed a body temperature of $37.8^{\circ} \mathrm{C}$, blood pressure of $128 / 75 \mathrm{mmHg}$, and pulse of 90 beats per minute. Given a history of preexisting asymptomatic gallstones, an abdominal CT and blood tests were conducted to reassess the abdomen. The diagnosis of acute calculous cholecystitis and common bile duct stones was confirmed by evident progression of a swollen gallbladder with thick wall and exudation, associated with common bile duct stones on the CT image (Figure $\mathrm{S} 1$ and Table 1).

A day later, the infective situation evolved rapidly to septic shock on 6 March 2020 , with a high fever of $39.1^{\circ} \mathrm{C}$, elevated heart rate of 130 beats per minute, and low blood pressure $(91 / 56 \mathrm{mmHg})$. The white cell count $(22,790$ per $\mu \mathrm{L})$, neutrophil count $(21,050$ per $\mu \mathrm{L})$, and infection related biomarkers, such as procalcitonin $(88.2 \mathrm{ng} / \mathrm{mL})$ and C-reactive protein $(>367.8 \mathrm{mg} / \mathrm{L})$, suddenly and simultaneously reached their peak (Table 1). The lymphocyte count declined to 490 per $\mu \mathrm{L}$ after biliary infection from
5 March 2020 (Table 1), a Gram-negative bacillus was also reported positive in the blood test on 6 March 2020, and Klebsiella pneumoniae was later identified in a blood culture.

Since anti-infective therapy did not relieve the infection, our multidisciplinary treatment (MDT) discussion resulted in the decision that removal of the primary infection focus and the common bile duct stones was the ultimately effective method for resolving severe acute biliary infection and relieving the bile duct pressure caused by symptomatic gallstones. We then performed an emergency procedure of cholecystectomy plus common bile duct exploration and T-tube placement on 6 March 2020. The surgical procedure was accomplished according to the guidelines of gallbladder stone and common bile duct stone removal (15). The gallbladder with acute gangrenous cholecystitis was resected and common bile duct stones were extracted successfully. An abdominal drainage was placed at the gallbladder fossa for postoperative observation. Although the results of oropharyngeal swab and stool sample were negative for SARS-CoV-2 when the operation was performed, to our knowledge there was no evidence of the viral status in bile reported, the surgical team performed this operation under 
the highest level of personal protective protocol (16).

After the emergency operation, the patient's vital signs stabilized and their situation gradually improved. The white cell count, neutrophil count, and infectionrelated biomarkers improved effectively (Table 1). A T-tube cholangiography was performed to evaluate clearance of the common bile duct stones on 20 March 2020 (Figure S1). The patient was discharged on 16 March 2020 and the T-tube was removed on 1 April 2020.

\section{Specimen collection}

The clinical specimens of the COVID-19 patient including serum, oropharyngeal swabs, sputum, bile, abdominal drainage fluid, urine, stool, and gallbladder tissue were collected in accordance with the Chinese Center for Disease Control and Prevention (CDC) guidelines. A fresh normal gallbladder tissue sample (female, 50 years old) was taken from the liver of a deceased donor after brain death donation for liver transplantation. A gangrenous gallbladder tissue sample was obtained from a patient (male, 50 years old) with acute gangrenous cholecystitis who underwent cholecystectomy on the same day.

All procedures performed in studies involving human participants were in accordance with the ethical standards of the institutional and/or national research committee(s) and with the Helsinki Declaration (as revised in 2013). Written informed consent was obtained from the patient for publication of this case report and accompanying images. A copy of the written consent is available for review by the editorial office of this journal.

\section{Quantitative polymerase chain reaction assay}

Clinical preoperative and postoperative specimens from the COVID-19 patient, including serum, oropharyngeal swab, sputum, bile, abdominal drainage fluid, urine, rectal swab, and stool, were collected and tested for SARS-CoV-2 RNA using the China CDC-standardized quantitative polymerase chain reaction (qPCR) assay (17).

\section{Hematoxylin-eosin (HE), immunobistochemistry (IHC), and immunofluorescent staining}

The gallbladder tissues were stained with $\mathrm{HE}$ and embedded with paraffin, and IHC was performed using the PV-9000 2-step Polymer Detection System (ZSGBBio., Beijing, China) and a Liquid DAB Substrate Kit
(Invitrogen, San Francisco, CA, USA) was used according to the manufacturer's instructions, as described in our previous studies (18). Detailed information of primary antibodies used in this study is shown in Table S1. We detected 5 hot zones of the positive immune cells in the images and scored the positive immune cells using an automated quantitative pathology imaging system with CaseViewer 2.2 (3DHISTECH, Budapest, Hungary). The steps of immunofluorescent imaging (IF) were performed as described previously (11). Briefly, $4 \mu \mathrm{m}$ thick sections were incubated with $10 \%$ goat serum in phosphate-buffered saline/Tween (PBST) for $1 \mathrm{~h}$ at room temperature and then incubated overnight at $4{ }^{\circ} \mathrm{C}$ with primary antibodies (antiACE2, Santa Cruz Biotechnology, Santa Cruz, CA, USA, sc-390851, 1:200; anti-NP, Sino Biological, Beijing, China; 40143-T62, 1:500). Then, the sections were visualized with secondary antibodies (Alexa Fluor647-conjugated goat anti-rabbit IgG, bs-0296G-AF647, Bioss, Woburn, MA, USA, 1:100; Dylight488-conjugated goat anti-mouse IgG, A23210, Abbkine, Wuhan, Hubei, China, 1:100) for $1 \mathrm{~h}$ at room temperature. Nuclei were then counterstained with 4',6-diamidino-2-phenylindole (DAPI) after washing with PBST. Slides were analyzed using a laser scanning confocal microscope (LSM880, Carl Zeiss MicroImaging, Oberkochen, Germany).

\section{Specimen testing for SARS-CoV-2}

As shown in Figure 1, the bile, as well as the serum, oropharyngeal swabs, sputum, abdominal drainage fluid, urine, and rectal swabs were consecutively collected after the operation and all tested negative for SARS-CoV-2 RNA from 6 March 2020 to 15 March 2020.

\section{SARS-CoV-2 infection in the gallbladder epithelial cells}

To further explore the evidence of SARS-CoV-2 gallbladder infection, a normal gallbladder and a gangrenous gallbladder were collected and compared by $\mathrm{HE}$ and IF staining, respectively (Figure 2). We conducted IF staining of ACE2 and viral nucleocapsid protein (NP) expression in these 3 gallbladder tissue samples. The results showed that ACE2 was highly expressed in the gallbladder epithelial cells of all 3 gallbladder tissues, and the positive staining of viral NP was visualized in the cytoplasm of gallbladder epithelial cells with SARS-CoV-2 infection, while the normal gallbladder and the gangrenous gallbladder without SARS-CoV-2 infection had negative in NP expression (Figure 2). 


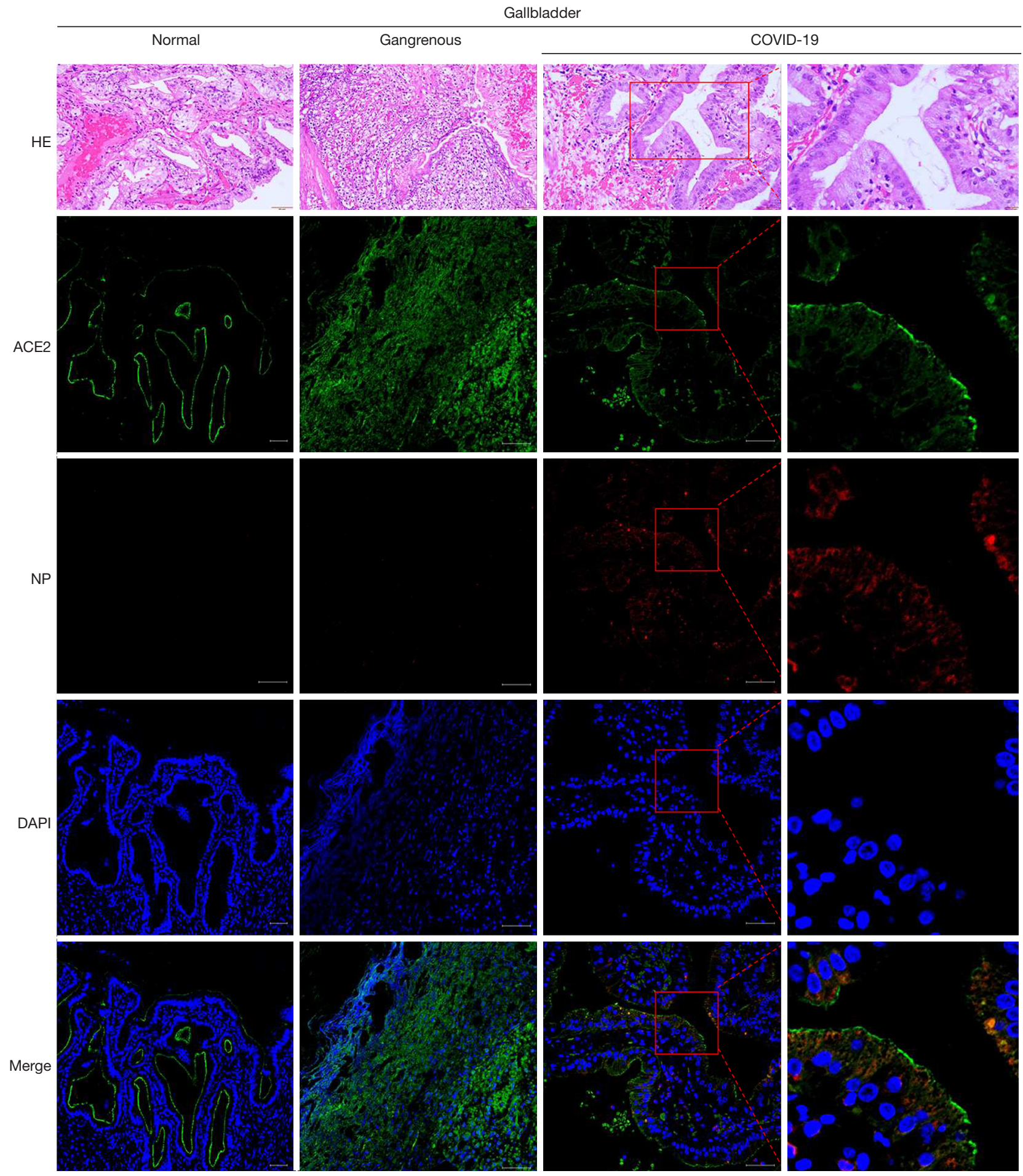

Figure 2 Images of histological and immunofluorescent staining of gallbladder tissues (scale bars, $50 \mu \mathrm{m}$ ). HE, hematoxylin and eosin; IHC, immunohistochemistry; IF, immunofluorescent; ACE2, angiotensin-converting enzyme 2; NP, nucleocapsid protein; DAPI, 4',6-diamidino2-phenylindole. 

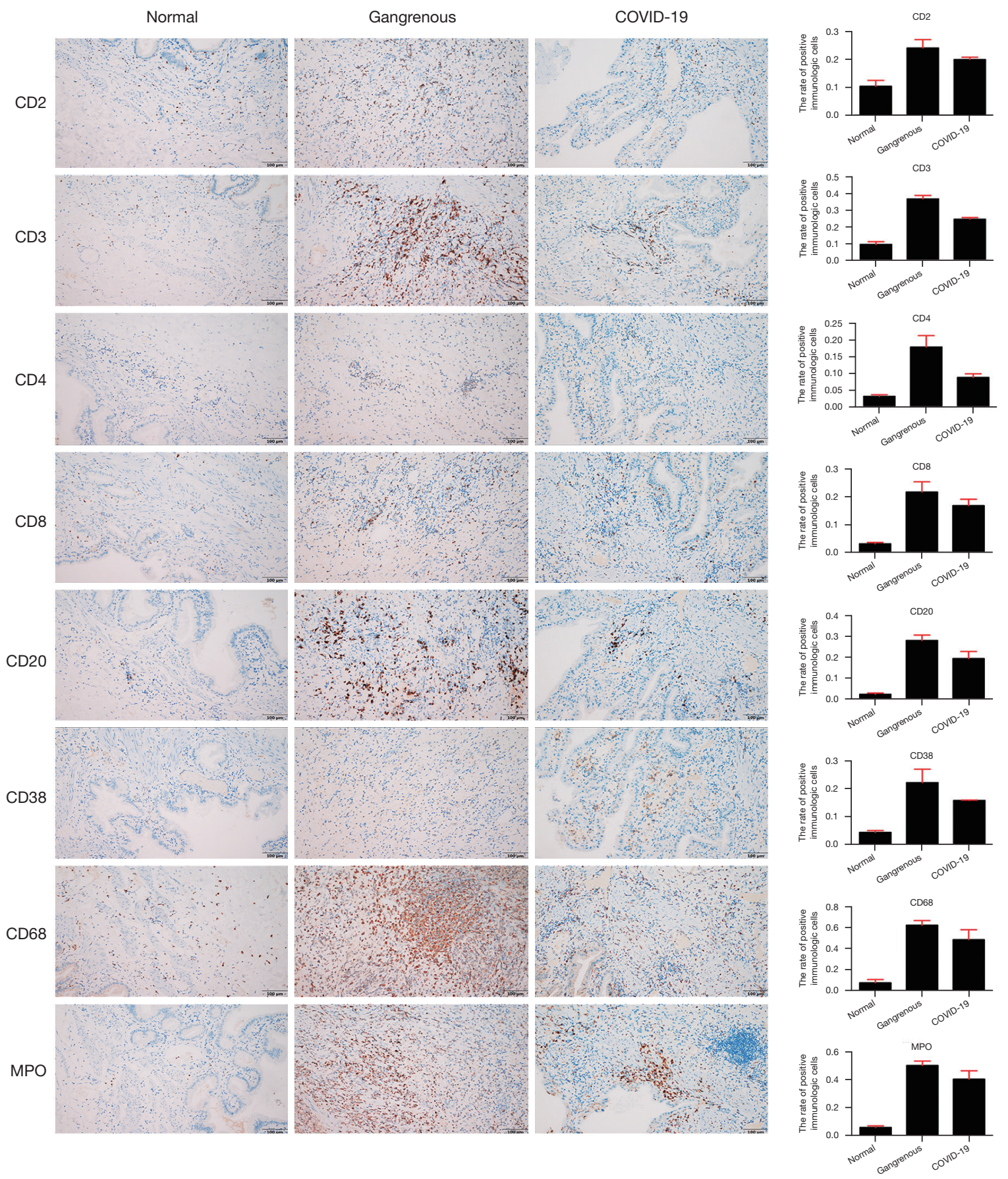

Figure 3 Images of immunohistological staining of gallbladder tissues. Images of immunohistological staining of the normal gallbladder, gangrenous gallbladder, and the gallbladder from the COVID-19 patient (scale bars, $50 \mu \mathrm{m}$ ). Histograms displayed on the right side of the image show the average positive percentage of the immunological cells in the normal gallbladder tissues (CD2: 10.32\%; CD3: 9.54\%; CD4: 1.42\%; CD8: 3.14\%; CD20: 2.36\%; CD38: 4.40\%; CD68: 7.52\%; MPO: 6.08\%), the gangrenous gallbladder (CD2: 24.04\% CD3: 36.73\%; CD4: 17.86\%; CD8: 21.65\%; CD20: 28.03\%; CD38: 22.23\%; CD68: 62.51\%; MPO: 51.64\%) and the gallbladder tissues from the COVID-19 patient (CD2: 19.89\%; CD3: 24.56\%; CD4: 8.77\%; CD8: 16.81\%; CD20: 19.41\%; CD38: 15.84\%; CD68: 42.29\%; MPO: $40.85 \%)$. 


\section{Immune cells in the gallbladder tissue with SARS-CoV-2 infection}

The total lymphocyte count and lymphocyte subpopulations in peripheral blood, such as $\mathrm{CD}^{+}, \mathrm{CD}^{+} \mathrm{CD}^{+}$, and $\mathrm{CD} 3^{+} \mathrm{CD} 8^{+}$lymphocytes, were observed to dramatically decline after biliary infection in the COVID-19 patient (Table 1 and Table S2). As shown in Figure 3, the immune cells including CD2, CD3, CD4, CD8, CD20, CD38, CD68, and MPO exhibited positive staining in gallbladder tissues with gangrenous cholecystitis (no matter with or without SARS-CoV-2 infection) while negative in normal gallbladder tissues. Notably, we found that the positive expressions of the stained immune cells were relatively downregulated in gallbladder tissue with SARS-CoV-2 infection (CD2: 19.89\%; CD3: 24.56\%; CD4: 8.77\%; CD8: 16.81\%; CD20: 19.41\%; CD38: 15.84\%; CD68: 42.29\%; MPO: $40.85 \%$ ) when compared with the gangrenous gallbladder without SARS-CoV-2 infection (CD2: 24.04\%; CD3: 36.73\%; CD4: 17.86\%; CD8: $21.65 \%$; CD20: 28.03\%; CD38: 22.23\%; CD68: 62.51\%; MPO: 51.64\%).

\section{Discussion}

In our study, we first demonstrated that viral host receptor ACE2 was highly expressed in gallbladder epithelial cells, and viral NP was visualized in the cytoplasm of gallbladder epithelial cells, which was considered direct evidence of SARS-CoV-2 infection in the gallbladder. This finding verified that the gallbladder was one of the target organs which SARS-CoV-2 could directly attack and damage using ACE2 as a host cell receptor $(7,8,19)$. In addition, for this special case, the stool first tested positive on 4 February 2020 and did not turn negative until 4 March 2020 , indicating that detoxification of the virus in the digestive system could exist for up to a month. This result was consistent with a previous study showing the prolonged presence of SARS-CoV-2 viral RNA in stool (20). Moreover, recent studies have reported that a positive test of viral RNA could relapse and the virus could remain in the lung tissues of recovered COVID-19 patients $(21,22)$. In this case, although the viral NP was positive in the cytoplasm of gallbladder epithelial cells, the bile obtained postoperatively from the T-tube tested negative for SARSCoV-2 RNA. We considered that oropharyngeal swab and stool testing negative for the virus, which we called "double negative", may be a reliable criterion of recovery from COVID-19 and a valid indicator of non-transmission through bile. Therefore, the highest defensive strategy of surgery in this case may not have been necessary. It is worth noting that confirmed COVID-19 patients with pre-existing gallstones may develop severe biliary infection which requires vigilant management and appropriate interventions including emergency surgery in the case of septic shock.

It has been verified that immune response could play a fundamental role in patients with SARS-CoV-2 infection (23). Cytokine storm was confirmed to be associated with over-exaggerated immune response and uncontrolled inflammatory response, which resulted in multiple organs damages in COVID-19 patients. Chen et al. indicated that immunologic cells including $\mathrm{CD}^{+}$and $\mathrm{CD} 8^{+} \mathrm{T}$ cells were markedly decreased in critical patients with COVID-19 (24). Given that patients with COVID-19 with gastrointestinal symptoms had reduced levels of circulating cytokines associated with inflammation and tissue damage (25), immune dysregulation might be the main cause aggravating cholecystitis to septic shock. According to our study, a dramatic decline in lymphocyte count and lymphocyte subpopulations were observed and the patient rapidly progressed into a severe acute biliary infection with sepsis, which demonstrated that viral infection in gallbladder might have been the original trigger, inflammation caused by immune dysregulation may play a more important role in this process of aggravation. The immune cells including CD2, CD3, CD4, CD8, CD20, CD38, CD68, and $\mathrm{MPO}$ were positive in gangrenous gallbladder tissues without SARS-CoV-2 infection, and were relatively downregulated in SARS-CoV-2 infective gallbladder tissue. We hypothesized that a strongly positive immune system response was the reasonable consequence after the gallbladder had been attacked by bacterial infection only; however, an additional SARS-CoV-2 viral infection may inhibit or destroy this positive immune response, which led to a more vulnerable status and aggravated the biliary infection to sepsis. Therefore, immune dysregulation caused by biliary infection of SARS-CoV-2 and comorbidity with acute calculous cholecystitis requires more vigilant management as well as early assessment and appropriate intervention, even in the early recovery stage or after hospital discharge.

This study provided evidence of SARS-CoV-2 infection in the gallbladder and verified that the gallbladder was one of the target organs that SARS-CoV-2 could attack and damage using ACE2 as a cell receptor. Due to the immune dysregulation involved, more vigilant management and early assessment is needed for COVID-19 patients with the 
comorbidity of cholecystitis.

\section{Acknowledgments}

Funding: This study was supported by COVID-19 Infection Prevention and Control Emergency Technology Project of Zhuhai City (ZH22036302200020PWC).

\section{Footnote}

Reporting Checklist: The authors have completed the CARE reporting checklist. Available at https://dx.doi. org/10.21037/atm-21-4778

Conflicts of Interest: All authors have completed the ICMJE uniform disclosure form (available at https://dx.doi. org/10.21037/atm-21-4778). The authors have no conflicts of interest to declare.

Etbical Statement: The authors are accountable for all aspects of the work in ensuring that questions related to the accuracy or integrity of any part of the work are appropriately investigated and resolved. All procedures performed in studies involving human participants were in accordance with the ethical standards of the institutional and/or national research committee(s) and with the Helsinki Declaration (as revised in 2013). Written informed consent was obtained from the patient for publication of this case report and accompanying images. A copy of the written consent is available for review by the editorial office of this journal.

Open Access Statement: This is an Open Access article distributed in accordance with the Creative Commons Attribution-NonCommercial-NoDerivs 4.0 International License (CC BY-NC-ND 4.0), which permits the noncommercial replication and distribution of the article with the strict proviso that no changes or edits are made and the original work is properly cited (including links to both the formal publication through the relevant DOI and the license). See: https://creativecommons.org/licenses/by-nc-nd/4.0/.

\section{References}

1. Guan WJ, Ni ZY, Hu Y, et al. Clinical Characteristics of Coronavirus Disease 2019 in China. N Engl J Med 2020;382:1708-20.

2. Zhou F, Yu T, Du R, et al. Clinical course and risk factors for mortality of adult inpatients with COVID-19 in Wuhan, China: a retrospective cohort study. Lancet 2020;395:1054-62.

3. Hokello J, Sharma AL, Shukla GC, et al. A narrative review on the basic and clinical aspects of the novel SARS$\mathrm{CoV}-2$, the etiologic agent of COVID-19. Ann Transl Med 2020;8:1686.

4. Ghinai I, McPherson TD, Hunter JC, et al. First known person-to-person transmission of severe acute respiratory syndrome coronavirus 2 (SARS-CoV-2) in the USA. Lancet 2020;395:1137-44.

5. Chan JF, Yuan S, Kok KH, et al. A familial cluster of pneumonia associated with the 2019 novel coronavirus indicating person-to-person transmission: a study of a family cluster. Lancet 2020;395:514-23.

6. Hindson J. COVID-19: faecal-oral transmission? Nat Rev Gastroenterol Hepatol 2020;17:259.

7. Hoffmann M, Kleine-Weber H, Schroeder S, et al. SARSCoV-2 Cell Entry Depends on ACE2 and TMPRSS2 and Is Blocked by a Clinically Proven Protease Inhibitor. Cell 2020;181:271-280.e8.

8. Wang Q, Zhang Y, Wu L, et al. Structural and Functional Basis of SARS-CoV-2 Entry by Using Human ACE2. Cell 2020;181:894-904.e9.

9. Zhang C, Shi L, Wang FS. Liver injury in COVID-19: management and challenges. Lancet Gastroenterol Hepatol 2020;5:428-30.

10. Ronco C, Reis T. Kidney involvement in COVID-19 and rationale for extracorporeal therapies. Nat Rev Nephrol 2020;16:308-10.

11. Xiao F, Tang $M$, Zheng $X$, et al. Evidence for Gastrointestinal Infection of SARS-CoV-2. Gastroenterology 2020;158:1831-1833.e3.

12. Qin C, Zhou L, Hu Z, et al. Dysregulation of Immune Response in Patients With Coronavirus 2019 (COVID-19) in Wuhan, China. Clin Infect Dis 2020;71:762-8.

13. Mehta P, McAuley DF, Brown M, et al. COVID-19: consider cytokine storm syndromes and immunosuppression. Lancet 2020;395:1033-4.

14. Henry BM. COVID-19, ECMO, and lymphopenia: a word of caution. Lancet Respir Med 2020;8:e24.

15. Williams E, Beckingham I, El Sayed G, et al. Updated guideline on the management of common bile duct stones (CBDS). Gut 2017;66:765-82.

16. Brindle ME, Gawande A. Managing COVID-19 in Surgical Systems. Ann Surg 2020;272:e1-2.

17. Li Q, Guan X, Wu P, et al. Early Transmission Dynamics in Wuhan, China, of Novel Coronavirus-Infected 
Pneumonia. N Engl J Med 2020;382:1199-207.

18. Liu W, He JZ, Wang SH, et al. MASAN: a novel staging system for prognosis of patients with oesophageal squamous cell carcinoma. Br J Cancer 2018;118:1476-84.

19. Li W, Moore MJ, Vasilieva N, et al. Angiotensinconverting enzyme 2 is a functional receptor for the SARS coronavirus. Nature 2003;426:450-4.

20. Wu Y, Guo C, Tang L, et al. Prolonged presence of SARSCoV-2 viral RNA in faecal samples. Lancet Gastroenterol Hepatol 2020;5:434-5.

21. Lan L, Xu D, Ye G, et al. Positive RT-PCR Test Results in Patients Recovered From COVID-19. JAMA 2020;323:1502-3.

22. Yao XH, He ZC, Li TY, et al. Pathological evidence for

Cite this article as: Hong $\mathrm{X}, \mathrm{He} \mathrm{J}, \mathrm{Li}$ P, Chen J, Zou B, Li Z, Jia Y, Liu Y, Yang L, Li J. Evidence of SARS-CoV-2 infection in gallbladder and aggravating cholecystitis to septic shock: a case report. Ann Transl Med 2021;9(21):1631. doi: 10.21037/atm$21-4778$ residual SARS-CoV-2 in pulmonary tissues of a ready-fordischarge patient. Cell Res 2020;30:541-3.

23. Pedersen SF, Ho YC. SARS-CoV-2: a storm is raging. J Clin Invest 2020;130:2202-5.

24. Chen G, Wu D, Guo W, et al. Clinical and immunological features of severe and moderate coronavirus disease 2019. J Clin Invest 2020;130:2620-9.

25. Livanos AE, Jha D, Cossarini F, et al. Intestinal host response to SARS-CoV-2 infection and COVID-19 outcomes in patients with gastrointestinal symptoms. Gastroenterology 2021;160:2435-2450.e34.

(English Language Editor: J. Jones) 

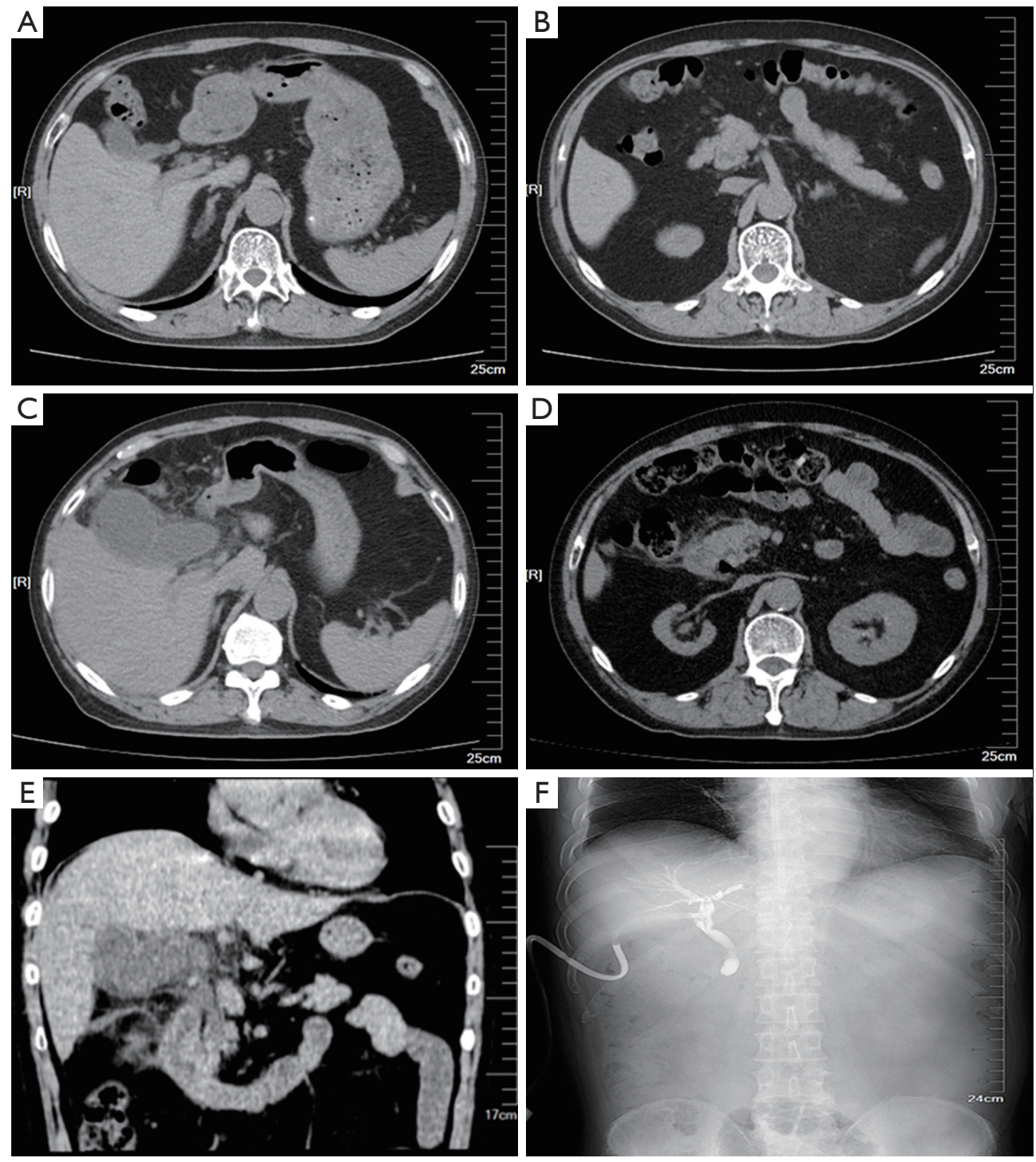

Figure S1 Representative abdominal imaging in the COVID-19 patients with biliary infection rapidly progressing to sepsis. Representative abdominal imaging from the COVID-19 patient, the abdominal CT scan on 17 February 2020 showed that the gallbladder was normal without edema and exudation (A) and the CBD stones were found at the inferior extremity of CBD (B). The gallbladder was swelling with thick wall and exudation (C) and the CBD stones was still at the inferior extremity of CBD (D) on 5 March 2020. After three-dimensional reconstruction, we found that the stone was in the neck of the gallbladder and the CBD was slightly dilated caused by the CBD stones (E). A T-tube cholangiography was conducted to make sure the clearance of the CBD stones on 20 March 2020 (F). COVID-19, coronavirus disease 2019; CT, computed tomography; CBD, common bile duct. 
Table S1 The detailed information of antibodies

\begin{tabular}{lccc}
\hline Antibody to & Mono/polyclonal & Clone & Application (dilution) \\
\hline CD2 & Mouse & AB75 & IHC (ready-to-use) \\
CD3 & Rabbit & SP7 & IHC (ready-to-use) \\
CD4 & Rabbit & EP204 & IHC (ready-to-use) \\
CD8 & Mouse & SP16 & IHC (ready-to-use) \\
CD20 & Mouse & L26 & IHC (ready-to-use) \\
CD38 & Mouse & MXO44 & IHC (ready-to-use) \\
CD68 & Mouse & KP1 & IHC (ready-to-use) \\
MPO & Rabbit & RAB-0379 & IHC (ready-to-use) \\
\hline
\end{tabular}

$\mathrm{IHC}$, immunohistochemistry.

Table S2 Results of lymphocyte subpopulations in peripheral blood of the patient with SARS-CoV-2 infection

\begin{tabular}{|c|c|c|c|c|c|c|c|c|c|c|c|c|}
\hline Parameter & $\begin{array}{l}\text { Reference } \\
\text { range }\end{array}$ & $\begin{array}{c}\text { Jan. } \\
30\end{array}$ & $\begin{array}{c}\text { Feb. } \\
1\end{array}$ & $\begin{array}{c}\text { Feb. } \\
2\end{array}$ & $\begin{array}{c}\text { Feb. } \\
3\end{array}$ & $\begin{array}{c}\text { Feb. } \\
5\end{array}$ & $\begin{array}{c}\text { Feb. } \\
7\end{array}$ & $\begin{array}{c}\text { Feb. } \\
9\end{array}$ & $\begin{array}{c}\text { Feb. } \\
11\end{array}$ & $\begin{array}{c}\text { Feb. } \\
13\end{array}$ & $\begin{array}{c}\text { Feb. } \\
15\end{array}$ & $\begin{array}{c}\text { Mar. } \\
7\end{array}$ \\
\hline $\mathrm{CD}^{+}$Iymphocytes count (per $\left.\mu \mathrm{L}\right)$ & $955-2,860$ & 1,054 & 905 & 1,512 & 1,920 & 1,741 & 1,469 & 1,292 & 1,066 & 1,142 & 1,180 & 68 \\
\hline $\mathrm{CD}^{+} \mathrm{CD}^{+}$lymphocytes count (per $\left.\mu \mathrm{L}\right)$ & $550-1,440$ & 596 & 538 & 926 & 1,184 & 1,037 & 882 & 826 & 650 & 723 & 795 & 40 \\
\hline $\mathrm{CD}^{+}{ }^{+} \mathrm{CD} 8^{+} \mathrm{T}$ cells count/lymphocytes count $(\%)$ & $15-44$ & 18.33 & 19.26 & 19.47 & 17.90 & 20.11 & 21.69 & 20.85 & 21.14 & 20.61 & 20.21 & 11.43 \\
\hline $\mathrm{CD}^{+} \mathrm{CD}^{+} / \mathrm{CD}^{+}{ }^{+} \mathrm{CD} 8^{+}$ratio & $0.71-2.78$ & 1.80 & 1.87 & 1.99 & 2.28 & 2.00 & 1.88 & 2.20 & 1.93 & 2.11 & 2.35 & 1.82 \\
\hline
\end{tabular}

